\title{
I. V. Oxytocin versus oral Misoprostol for augmentation of labour, associated complications and effect on neonatal wellbeing
}

\author{
Swapnil Wilson, Subrata Das*
}

Department of Obstetrics and Gynecology, LAMGMC Raigarh and KGH Hospital, Raigarh, Chhattisgarh, India

Received: 09 June 2018

Accepted: 03 July 2018

\section{*Correspondence:}

Dr. Subrata Das,

E-mail: bhagatgreat@gmail.com

Copyright: (c) the author(s), publisher and licensee Medip Academy. This is an open-access article distributed under the terms of the Creative Commons Attribution Non-Commercial License, which permits unrestricted non-commercial use, distribution, and reproduction in any medium, provided the original work is properly cited.

\begin{abstract}
Background: The complications of prolonged labor are well recognized and the caesarean section has been used liberally. But even then, prolonged labor continues to be a problem. This could be due to weak uterine contractions or poor cervical dilatation. The problem can be overcome with the use of oxytocic drugs. The aim of the study was to compare the efficacy, adverse effects, safety, and feto-maternal outcome of the ARM and oral misoprostol with Artificial Rupture of Membrane (ARM) and oxytocin infusion for labor augmentation.

Methods: This prospective study was conducted in the labor room of NRS Medical College and Hospital Kolkata and included 100 primigravidae women carrying singleton pregnancy at term with spontaneous onset of labor.

Results: The result findings of the present study show that the prolonged labor was the major indication for LSCS in both the groups. There was a significantly higher subjects $\left(\mathrm{P}<0.05^{*}\right)$ had fetal distress or fetal bradycardia, meconium staining of liquor, Tachysystole in the misoprostol group, compared to oxytocin group. No significant difference was observed among the groups with respect to neonatal wellbeing.

Conclusions: Both the agents i.e. oral misoprostol and I.V. oxytocin shortens the duration of labor effectively and are effective for augmentation of labor. Apart from Tachysystole and meconium staining of liquor and fetal distress the incidence of any other complication was not significantly more in the oral misoprostol group when compared with oxytocin group. Status of the neonate was almost similar in both the groups.
\end{abstract}

Keywords: ARM, Labor, Misoprostol, Oxytocin

\section{INTRODUCTION}

The complications of prolonged labor are well recognized and the caesarean section has been used liberally. But even then, prolonged labor continues to be a problem. This could be due to weak uterine contractions or poor cervical dilatation. The problem can be overcome with the use of oxytocic drugs. ${ }^{1-4}$

Traditionally there are surgical and medical methods of augmentation of labor. For medical method oxytocin is used for many years. It is the old age procedure to augment labor using intravenous oxytocin, but prostaglandin is a newer drug. It can be used as a cervical gel, vaginal tablet or oral route. The oral route is convenient to the patient as well as to doctor. Misoprostol is not well practiced in many centers but its efficacy put us to think about as an alternative to oxytocin.,

Various complications may arise during the course of labor. Prolonged and obstructed labor can cause considerable maternal and fetal morbidity and mortality, especially in the developing world due to sepsis, rupture of the uterus and postpartum hemorrhage. In India 
incidence of obstructed labor is about 1 to $5 \%$ depending upon the health and transport facilities available and it contributes to about $10 \%$ of maternal deaths. ${ }^{7}$ In the developed world, cesarean section rates for dystocia or difficult labor are on the rise and contribute to at least one-third of the overall cesarean section rates. Repeat section after primary cesarean section accounting for another third. Cesarean section leads to increased maternal mortality and morbidity, especially when performed as an emergency procedure (the risk increases to 9-fold). ${ }^{8,7}$ The concept of partotography was introduced by Friedman in New-York in 1954, "the graphic analysis of labor". ${ }^{9,10}$ From his studies, Friedman concluded that progressive dilatation of cervix was the most important factor in assessing the progress of labor.

He, therefore, plotted cervical dilatation against time on his graph. The present-day partograph recommended by WHO, incorporates many relevant parameters related to labor, including cervical dilatation, descent of the presenting part (assessed abdominally in fifths of the head palpable above the pelvic brim), fetal heart rate, frequency and duration of uterine contractions, the color and quantity of amniotic fluid passed, maternal parameters like temperature, pulse and blood pressure and the drugs used..$^{11,12}$ When the cervicography crosses the alert and action line too as evidenced by flattening of the curve, the obstetrician has to decide and take necessary action like amniotomy, augmentation with oxytocin, prostaglandin or cesarean section.

In this background of the lacunae of our present knowledge, the need for augmentation of labor is evident. While the standard agents like oxytocin have been studied extensively, newer agents like PGE1 (misoprostol) present a field relatively unexplored. ${ }^{13,14} \mathrm{~A}$ thorough comparison between the standard agents and the newer agents has become necessary. So, the present study will reveal the pros and cons of oxytocin infusion and oral misoprostol in terms of, efficacy, safety, ease of application, availability and possible adverse fetomaternal effects.

\section{METHODS}

This prospective study was conducted in the labor room of NRS Medical College and Hospital Kolkata and included 100 primigravidae women carrying singleton pregnancy at term with spontaneous onset of labor. The study was conducted during the period from May 2011 to April 2012.

\section{Study population}

Patients aged between 18 to 28 years, primigravidae between 37 to 42 weeks of gestational age, live singleton pregnancy, cephalic presentation, spontaneous onset of labor, cervical dilatation of $4 \mathrm{~cm}$ or more, inadequate uterine contractions less than three per 10 minutes, reassuring foetal heart rate and giving informed consent were included in the study. Patients with PROM, multiple pregnancies, polyhydramnios, non-cephalic presentation, probable CPD, suspected IUGR, scarred uterus, uterine perforation and medical diseases like heart disease, bronchial asthma etc. were excluded from the study.

\section{Data collection and sampling technique}

The institutional ethics committee of NRS Medical College and Hospital Kolkata approved this study protocol. Informed written consent was obtained from all study participants. They were counseled thoroughly prior to giving consent. A thorough general, systemic and obstetrical examination was done.

Assigning of the cases was done by simple random sampling. Each of the agents was applied to every alternate case, likewise 50 cases were allocated in the misoprostol group, where augmentation was done by oral misoprostol $25 \mathrm{mcg}$ at 4-hour interval to maximum of 3 doses (henceforth referred as misoprostol group) and another 50 cases were allocated in the oxytocin intravenous infusion (henceforth be known as oxytocin group). Oxytocin infusion was started at the minimum dose of $2 \mathrm{mIU} / \mathrm{min}$ in Ringer lactate solution, adjusting the dose every 15 minutes till the desired uterine contractions are achieved, with a maximum dose of $5 \mathrm{mIU} / \mathrm{min}$ at the rate of 15 to 20 drops per minute. The patients were observed during this process of augmentation for fetal bradycardia or tachycardia, Tachysystole, hypercontraction, and color of the liquor. All the different parameters were noted on the partograph. Per vaginal examination was repeated every 4 hours and non-progress of labor was declared when there was minimal or no change in cervicography, as evidenced by flattening of the curve. In any case of confirmed fetal distress or in cases of confirmed non-progress in the first stage of labor termination of pregnancy was done by cesarean section.

The tools used for this study include self-developed clinical and demographic data sheet. Digital obstetric $\mathrm{p} / \mathrm{v}$ examination was done for initial assessment of the state of dilatation of the internal os, effacement of cervix, position, and station of fetal head and assessment of pelvis. Auscultation by stethoscope was used to monitor the fetal heart sound. When FHS was doubtful, the handheld Doppler or USG machine available at labor room were used to confirm the fetal cardiac activity and to determine the fetal heart rate. The whole process of labor was plotted on the partograph and any deviation from the normal curve was undertaken for appropriate action.

\section{Statistical analysis}

The data analysis was done with the help of SPSS 22. Data were recorded as mean, and percentage. Different variables were compared between the two groups by Fisher's exact test and chi-square test. The analysis was 
two-tailed and a $P$ value of $<0.05$ was considered statistically significant. All the variables were calculated by \pm 2 standard deviations.

\section{RESULTS}

The present study was conducted in the labor room of NRS Medical College and Hospital Kolkata and included $\mathrm{N}=100$ primigravidae women carrying singleton pregnancy at term with spontaneous onset of labor, and the majority of the subjects belong to the age group of $20-30$ years $(n=37,74 \%$ and $n=38,76 \%$ respectively).
The age distribution of the subjects in these two groups was almost similar.

There was a significantly higher subjects $\left(P<0.05^{*}\right)$ had fetal distress or fetal bradycardia in the misoprostol group $(\mathrm{n}=6,12 \%)$, compared to oxytocin group $(\mathrm{n}=1,2 \%)$. There was a significantly higher $\left(P<0.05^{*}\right)$ subject had meconium staining of liquor in the misoprostol group (n $=7,14 \%)$, compared to oxytocin group $(\mathrm{n}=1,2 \%)$. There was a significantly higher subjects $\left(P<0.05^{*}\right)$ had Tachysystole in the misoprostol group $(\mathrm{n}=6,12 \%)$, compared to oxytocin group $(\mathrm{n}=1,2 \%)$.

Table 1: Complications during delivery in both the groups.

\begin{tabular}{|c|c|c|c|c|c|c|}
\hline Complications & & Misoprostol (n) & Oxytocin (n) & $\chi^{2}$ & df & $P$ value \\
\hline \multirow{2}{*}{ Foetal distress } & Foetal bradycardia or tachycardia & 6 & 1 & 3.84 & 1 & $<0.05^{*}$ \\
\hline & No fetal distress & 44 & 49 & & & \\
\hline \multirow{2}{*}{ Liquor meconium } & stained & 7 & 1 & 4.89 & 1 & $<0.05^{*}$ \\
\hline & not stained & 43 & 49 & & & \\
\hline \multirow{2}{*}{ Uterine contractions } & Tachysystole & 6 & 1 & 3.8409 & 1 & $<0.05^{*}$ \\
\hline & Normal uterine contractions & 44 & 49 & & & \\
\hline \multirow{2}{*}{ Hypertonicity } & Hypertonicity Present & 1 & 0 & 1.01 & 1 & 0.12 \\
\hline & No hypertonicity & 49 & 50 & & & \\
\hline \multirow{2}{*}{ PPH } & PPH Present & 2 & 2 & 0 & 1 & 0.45 \\
\hline & No PPH & 48 & 48 & & & \\
\hline
\end{tabular}

Table 2: Various parameters of neonatal wellbeing in both the groups.

\begin{tabular}{|c|c|c|c|c|c|c|}
\hline Neonatal wellbeing & & Misoprostol & Oxytocin & $\chi^{2}$ & df & $P$ value \\
\hline \multirow{2}{*}{ Need for resuscitation } & Crying after resuscitation & 2 & 1 & 0.34 & 1 & 0.17 \\
\hline & Crying before resuscitation & 48 & 49 & & & \\
\hline \multirow{2}{*}{ APGAR score } & Below 7 (asphyxia) & 5 & 1 & 2.83 & 1 & 0.32 \\
\hline & Above 7 (no asphyxia) & 45 & 49 & & & \\
\hline \multirow{2}{*}{ Mean APGAR score } & At 1 minute & 8.18 & 8.34 & 1.45 & 1 & 0.41 \\
\hline & At 5 minutes & 9.36 & 9.74 & & & \\
\hline \multirow{2}{*}{ Need for NICU admission } & Needed & 2 & 1 & 0.34 & 1 & 0.11 \\
\hline & Not needed & 48 & 49 & & & \\
\hline
\end{tabular}

In the misoprostol group, hypertonicity was seen in 1 subject $(2 \%)$ and in the oxytocin group, no occurrence of hypertonicity was seen. In the misoprostol group, PPH was seen in 2 subjects (4\%) while in oxytocin group PPH was seen in 2 subjects $(4 \%)$. No significant difference was observed for hypertonicity and PPH among the groups (Table 1).

In the misoprostol group, 2 babies (4\%) cried after resuscitation, APGAR score was less than 7 in 5 cases (10\%), mean APGAR scores at 1 minute 8.18 , at 5 minutes 9.36 and 2 subjects (4\%) needed NICU admission. In the oxytocin group, 1 baby $(2 \%)$ cried after resuscitation, APGAR score was less than 7 in 1 case (2\%), mean APGAR scores at 1 minute 8.34, at 5 minutes 9.74 and only 1 subject (2\%) needed NICU admission.
No significant difference was observed among the groups with respect to neonatal wellbeing (Table 2).

\section{DISCUSSION}

Prolonged labor due to weak uterine contractions or poor cervical dilatation is a major complication during labor and the problem can be overcome with the use of oxytocic drugs. ${ }^{1}$

Present study findings show that the incidence of lower segment cesarean section was highest in both the groups followed by forceps delivery and the percentage of various modes of delivery was almost similar in both the groups. Similar results were found in studies done by Ho et al and Villano et al. ${ }^{15,16}$ 
There was a significantly increased incidence of fetal distress (as evidenced by fetal bradycardia or tachycardia), meconium stained liquor and tachysystole found in the misoprostol group. The occurrence of hypertonicity was noted in $2 \%$ of the misoprostol group and in no subject (nil) in the oxytocin group. In this regard, a statistical comparison between the two groups was not feasible. The incidence of PPH was similar in both the groups. Actually, the low dose of misoprostol (25 mcg) used in this study might not have been able to cut short the rate of PPH. A similar study by Bleich, Alexander, McIntire and Leveno concluded that women in the misoprostol group were more likely to experience uterine tachysystole compare with those in the oxytocin group. ${ }^{17}$

Study findings show that the association of neonatal asphyxia, need for resuscitation and NICU admission after delivery with misoprostol was not significantly different as compared to oxytocin. The arithmetic mean of the APGAR score at 1 minute and 5 minutes in both the groups were almost similar. A study by Winikoff et al and Tolosa, Salati found similar results and concluded that the neonatal complications are independent of the administration of oxytocic drugs. ${ }^{18}$

The major disadvantage of the oxytocin injection was that it needed storage in the refrigerator and had to be brought out shortly before administration otherwise its efficacy would get lost. But misoprostol tablets did not require cold chain for maintenance of its efficacy. Moreover, the administration of the misoprostol tablet was easier as it had just to be given orally. On the other hand, oxytocin infusion needed ringer's solution for dilution infusion set and intravenous channel for its administration. So, its administration posed little difficulty.

\section{CONCLUSION}

Patients in the active phase of labor with poor uterine contraction and slow dilatation of the cervix, both the agents i.e. oral misoprostol and I.V. oxytocin shortens the duration of labor effectively and are effective for augmentation of labor. Apart from Tachysystole and meconium staining of liquor and fetal distress the incidence of any other complication was not significantly more in the oral misoprostol group when compared with oxytocin group. Status of the neonate was almost similar in both the groups. Moreover, it was easier to administer oral misoprostol as compares to intravenous oxytocin, but this context is of little concern. Oxytocin is an old drug for labor augmentation, but this study reveals that due to its easy availability and ease of application oral misoprostol has a slight edge over intravenous oxytocin. It was not a double-blind study and it was the limitation of the study, in future it can be overcome.

Funding: No funding sources

Conflict of interest: None declared
Ethical approval: The study was approved by the Institutional Ethics Committee

\section{REFERENCES}

1. O'Driscoll K, Foley M, MacDonald D. Active management of labor as an alternative to cesarean section for dystocia. Obstet Gynecol. 1984;63(4):485-90.

2. Rogers R, Gilson GJ, Miller AC, Izquierdo LE, Curet LB, Qualls CR. Active management of labor: does it make a difference? Am J Obstet Gynecol. 1997;177(3):599-605.

3. Brown HC, Paranjothy S, Dowswell T, Thomas J. Package of care for active management in labour for reducing caesarean section rates in low-risk women. Cochrane Database Syst Rev. 2008;4.

4. Nicholson JM, Parry S, Caughey AB, Rosen S, Keen A, Macones GA. The impact of the active management of risk in pregnancy at term on birth outcomes: a randomized clinical trial. Am J Obstet Gynecol. 2008;198(5):511-e1.

5. Thornton JG, Lilford RJ. Active management of labour: current knowledge and research issues. BMJ. 1994;309(6951):366-9.

6. Sadler LC, Davison T, McCowan LM. A randomised controlled trial and meta-analysis of active management of labour. BJOG. 2000;107(7):909-15.

7. Cunningham, Leveno, Hauth B, Rouse, Spong. Williams Obstetrics. 23 ${ }^{\text {rd }}$ edition. Mc. Graw Hill; 2009;21:490-499.

8. Clark SL, Belfort MA, Dildy GA, Herbst MA, Meyers JA, Hankins GD. Maternal death in the $21^{\text {st }}$ century: causes, prevention, and relationship to cesarean delivery. Am J Obstet Gynecol. 2008;199(1):36-e1.

9. Friedman E. The graphic analysis of labor. Am J Obstet Gynecol. 1954;68:1568-75.

10. Friedman EA. Primigravid labor: a graphicostatistical analysis. Obstet Gynecol. 1955;6:567-89.

11. Orji E. Evaluating progress of labor in nulliparas and multiparas using the modified WHO partograph. Int $\mathbf{J}$ Gynecol Obstet. 2008;102(3):249-52.

12. Philpott RH, Castle WM. Cervicographs in the management of labour in primigravidae: I. The alert line for detecting abnormal labour. BJOG: An Int J Obstet Gynaecol. 1972 Jul;79(7):592-8.

13. World Health Organization. Coverage of Maternity Care. A listing of available information. $4^{\text {th }}$ edition. Geneva: World Health Organization. 1997. Available at

http://apps.who.int/iris/bitstream/handle/10665/6387 8/WHO_RHT_MSM_96.28_\%28part1\%29.pdf?sequ ence $=1 \&$ is Allowed $=\mathrm{y}$

14. World Health Organization. The partograph. Sections 1,2,3,4. WHO/MCH/88.4. Geneva: WHO; 1988.

15. Ho M, Cheng SY, Li TC. Titrated oral Misoprostol solution compared with intravenous oxytocin for 
labor augmentation: a randomized controlled trial. Obstet Gynecol. 2010;116(3):612-8.

16. Villano KS, Lo JY, Alexander JM, McIntire DD, Leveno KJ. A dose-finding study of oral misoprostol for labor augmentation. Am J Obstet Gynecol. 2011;204(6):560-e1.

17. Bleich AT, Alexander JM, McIntire DD, Leveno KJ. An analysis of second-stage labor beyond 3 hours in nulliparous women. Am J Perinatol. 2012;29(09):717-22.

18. Winikoff B, Dabash R, Durocher J, Darwish E, Ngoc NT, León W, et al. Treatment of post-partum haemorrhage with sublingual misoprostol versus oxytocin in women not exposed to oxytocin during labour: a double-blind, randomised, non-inferiority trial. The Lancet. 2010;375(9710):210-6.

19. Tolosa JE, Salati J. Third stage of labor. In: Obstetric Evidence Based Guidelines. $3^{\text {rd }}$ Ed. CRC Press; 2017;27:121-8.

Cite this article as: Wilson S, Das S. I. V. Oxytocin versus oral Misoprostol for augmentation of labour, associated complications and effect on neonatal wellbeing. Int J Reprod Contracept Obstet Gynecol 2018;7:3338-42. 